Check for updates

Cite this: RSC Adv., 2018, 8, 31538

Received 3rd August 2018

Accepted 4th September 2018

DOI: 10.1039/c8ra06544f

rsc.li/rsc-advances

\title{
Polyellisin, a novel polyketide from cultures of the basidiomycete Polyporus ellisii $\uparrow$
}

\author{
Shuang Wang, ${ }^{\text {ab }}$ Zheng-Hui Li, ${ }^{a}$ Hong-Lian Ai, ${ }^{a}$ Juan He, ${ }^{a}$ Tao Feng (D) *a \\ and Ji-Kai Liu*a
}

Polyellisin (1), an unprecedented polyketide possessing a tricyclic system sharing a spiroketal carbon, was isolated from cultures of the basidiomycete Polyporus ellisii. The structure with absolute configuration was elucidated by means of spectroscopic methods and the single crystal X-ray diffraction. Polyellisin showed NO production inhibition with an $\mathrm{IC}_{50}$ value of $17.2 \mu \mathrm{M}$.

\section{Introduction}

The basidiomycete Polyporus ellisii, belonging to the family Polyporaceae, is widely distributed in the Yunnan and Sichuan Provinces of China. ${ }^{1}$ Its young fruiting body is used as a popular and delicious food in southwestern China, Japan and Korea. So far, the reports of chemical investigations on the species are not too many and have mainly been carried out by our research group. At first, a number of biologically active cerebrosides were isolated from its fruiting bodies. ${ }^{2-4}$ After that, a number of ergosterols ${ }^{5}$ and sesquiterpenoids ${ }^{6}$ were obtained from cultures of this fungus in 2013. In our continuing search for structurally interesting and biologically active natural products from higher fungi, ${ }^{5-12}$ an unprecedented polyketide, named polyellisin (1, Fig. 1), was isolated from cultures of the fungus $P$. ellisii. The structure was identified by means of spectroscopic methods, while its absolute configuration was determined by the single crystal X-ray diffraction. Polyellisin possesses a 6/6/6 tricyclic system sharing a spiroketal carbon. Its cytotoxicity against five human cancer cell lines and its ability to inhibit NO production were evaluated. Herein, the isolation, structural elucidation, and the biological activities of polyellisin are discussed.

\section{Results and discussion}

Polyellisin (1) had a molecular formula $\mathrm{C}_{20} \mathrm{H}_{28} \mathrm{O}_{6}$ as determined on the basis of the positive HRESIMS, which showed a molecular ion peak at $m / z 387.1779$ (calcd for $\mathrm{C}_{20} \mathrm{H}_{28} \mathrm{O}_{6} \mathrm{Na}, 387.1783$ ), corresponding to seven degrees of unsaturation. The IR spectrum indicated the presence of hydroxy group $\left(3438 \mathrm{~cm}^{-1}\right)$, carbonyl group $\left(1708 \mathrm{~cm}^{-1}\right)$ and double-bonds (1623,

${ }^{a}$ School of Pharmaceutical Sciences, South-Central University for Nationalities, Wuhan 430074,China.E-mail: tfeng@mail.scuec.edu.cn; jkliu@mail.kib.ac.cn ${ }^{b}$ College of Pharmacy and Chemistry, Dali University, Dali 671000, China $\dagger$ Electronic supplementary information (ESI) available: One PDF document. CCDC 936912. For ESI and crystallographic data in CIF or other electronic format see DOI: $10.1039 / \mathrm{c} 8 \mathrm{ra06544f}$
$1593 \mathrm{~cm}^{-1}$ ). The 1D NMR spectra, as well as the HSQC spectrum, revealed seven methyls (one methoxy), five methines, and eight quaternary carbons (Table 1 ). Of them, one olefinic proton at $\delta_{\mathrm{H}} 7.18(\mathrm{~s}, \mathrm{H}-3)$, together with six olefinic carbon resonances indicated the presence of a five substituted benzene ring A (Fig. 1). The locations of substituent groups in the benzene ring were established by HMBC and ROESY spectra. In the ROESY spectrum, the olefinic proton at $\delta_{\mathrm{H}} 7.18(\mathrm{~s}, \mathrm{H}-3)$ showed ROESY correlations to $2.21(3 \mathrm{H}, \mathrm{s}, \mathrm{Me}-18)$ and $\delta_{\mathrm{H}} 2.20(3 \mathrm{H}, \mathrm{s}, \mathrm{Me}-19)$, indicating that the two methyls should be located at C-2 and $\mathrm{C}-4$. While in the HMBC spectrum, the key HMBC correlation from $\mathrm{H}-3$ to the oxygenated carbons at $\delta_{\mathrm{C}} 153.0(\mathrm{~s})$ and 157.0 (s) revealed that these two olefinic carbons were assigned to $\mathrm{C}-1$ and C-5. The carbonyl carbon at $\delta_{\mathrm{C}} 191.8$ (s) was identified to be connected to $\mathrm{C}-6$ of the benzene ring. In the ${ }^{1} \mathrm{H}-{ }^{1} \mathrm{H}$ COSY spectrum, a partial moiety was established as shown in Fig. 2. In addition, a key HMBC correlation from $\delta_{\mathrm{H}} 3.70(1 \mathrm{H}, \mathrm{dq}, J=12.3$, $6.2 \mathrm{~Hz}, \mathrm{H}-13)$ to $\delta_{\mathrm{C}} 107.8$ (s, C-9) was detected. These data constructed a six-membered ether ring B (Fig. 2). Except the carbon resonances included in rings $\mathrm{A}$ and $\mathrm{B}$, the rest including a carbonyl carbon at $\delta_{\mathrm{C}} 191.8(\mathrm{~s}, \mathrm{C}-7)$, an $\mathrm{sp}^{3}$ quaternary carbon at $\delta_{\mathrm{C}} 76.2(\mathrm{~s}, \mathrm{C}-8)$, and a methyl carbon at $\delta_{\mathrm{C}} 18.0(\mathrm{q}, \mathrm{C}-17)$ are likely to build a six-membered ether ring $\mathrm{C}$ (Fig. 1), as deduced from the HMBC correlations from $\delta_{\mathrm{H}} 1.44(3 \mathrm{H}, \mathrm{s}, \mathrm{Me}-17)$ to C-7,

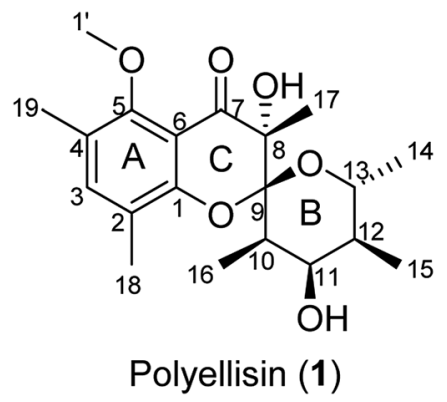

Fig. 1 Polyellisin (1) from cultures of the fungus Polyporus ellisii. 
Table $1{ }^{1} \mathrm{H}(500 \mathrm{MHz})$ and ${ }^{13} \mathrm{C}(125 \mathrm{MHz})$ NMR Data of $1^{a}$ in $\mathrm{CDCl}_{3}(\delta$ in ppm)

\begin{tabular}{|c|c|c|}
\hline & $\delta_{\mathrm{H}}(J$ in $\mathrm{Hz})$ & $\delta_{\mathrm{C}}$, type \\
\hline 1 & & 153.0, qC \\
\hline 2 & & $120.5, \mathrm{qC}$ \\
\hline 3 & $7.18 \mathrm{~s}$ & 139.0, CH \\
\hline 4 & & $125.2, \mathrm{qC}$ \\
\hline 5 & & $157.0, \mathrm{qC}$ \\
\hline 6 & & 112.0, qC \\
\hline 7 & & 191.8, qC \\
\hline 8 & & 76.2, qC \\
\hline 9 & & $107.8, \mathrm{qC}$ \\
\hline 10 & $2.30 \mathrm{qd}(7.2,3.1)$ & $38.3, \mathrm{CH}$ \\
\hline 11 & 3.58 br d (9.4) & $74.9, \mathrm{CH}$ \\
\hline 12 & $1.53 \mathrm{qd}(7.0,3.0)$ & $42.0, \mathrm{CH}$ \\
\hline 13 & $3.70 \mathrm{dq}(12.3,6.2)$ & $68.0, \mathrm{CH}$ \\
\hline 14 & $1.07 \mathrm{~d}(6.2)$ & 18.9, $\mathrm{CH}_{3}$ \\
\hline 15 & $0.98 \mathrm{~d}(7.0)$ & $13.8, \mathrm{CH}_{3}$ \\
\hline 16 & $1.25 \mathrm{~d}(7.2)$ & 13.2, $\mathrm{CH}_{3}$ \\
\hline 17 & $1.44 \mathrm{~s}$ & $18.0, \mathrm{CH}_{3}$ \\
\hline 18 & $2.21 \mathrm{~s}$ & $15.8, \mathrm{CH}_{3}$ \\
\hline 19 & $2.20 \mathrm{~s}$ & 14.9, $\mathrm{CH}_{3}$ \\
\hline $\mathrm{OMe}$ & $3.76 \mathrm{~s}$ & $61.0, \mathrm{CH}_{3}$ \\
\hline
\end{tabular}

${ }^{a}$ Data were assigned by HSQC, HMBC, ${ }^{1} \mathrm{H}-{ }^{1} \mathrm{H}$ COSY and ROESY spectra.

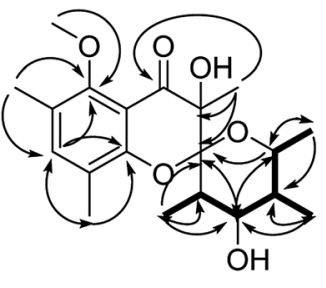

${ }^{1} \mathrm{H}-{ }^{1} \mathrm{H}$ COSY $\mathrm{HMBC} \overparen{\mathrm{H} \mathrm{C}}$

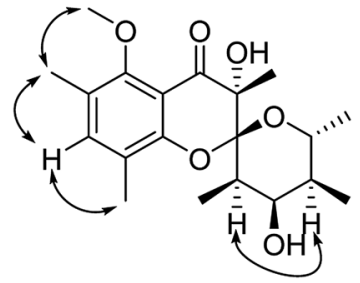

ROESY $\stackrel{\mathrm{H}}{\mathrm{H}}$
Fig. 2 Key 2D NMR correlations of 1.

C-8, and C-9, as well as from the mass spectroscopic data. Therefore, the gross structure of $\mathbf{1}$ was established as depicted.

Since multiple chiral centers and adjacent quaternary carbons, the relative configuration of $\mathbf{1}$ could not be identified by the ROESY experiment. Only the ROESY correlation between $\mathrm{H}-10$ and $\mathrm{H}-12$ could indicated that the Me- 15 and Me-16 were equatorial (Fig. 2). Fortunately, a single crystal X-ray diffraction not only confirmed the structure elucidation above but also established the absolute configuration as shown in Fig. 3.

Compound 1 was evaluated for its cytotoxicity against five human cancer cell lines, SK-BR-3 breast, SMMC-7721 hepatocellular carcinoma, HL-60 myeloid leukemia, PANC-1 pancreatic cancer and A-549 lung cancer, using the MTT method reported previously ${ }^{13}$ with minor revision. Unfortunately, the results showed that $\mathbf{1}$ exhibited no significant inhibitory activities with $\mathrm{IC}_{50}$ values more than $40 \mu \mathrm{M}$. In addition, compound 1 was evaluated for its anti-inflammatory activity using the method of the NO production inhibition, as that we reported recently. ${ }^{14}$ The result suggested that compound 1 possessed certain NO production inhibition with an $\mathrm{IC}_{50}$ value of $17.2 \mu \mathrm{M}$.

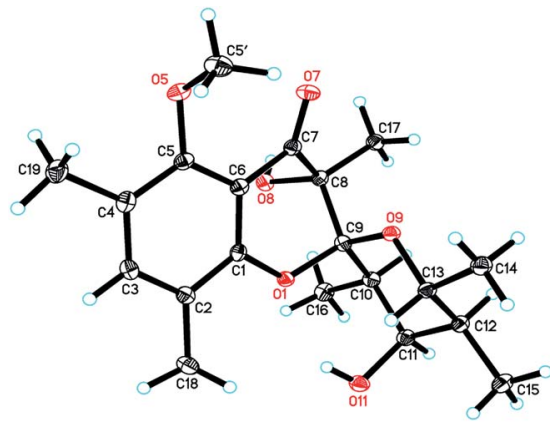

Fig. 3 ORTEP drawings of polyellisin (1).

\section{Conclusions}

In summary, the chemical investigation on the edible mushroom of $P$. ellisii was carried out, which resulted in the isolation of a novel polyketide, namely polyellisin (1). It possessed a tricyclic system sharing a spiroketal carbon, and the absolute configuration was determined by the single crystal X-ray diffraction. Polyellisin showed certain NO production inhibitory activity, suggesting a potential anti-inflammatory candidate.

\section{Experimental section}

\section{General experimental procedures}

The melting points were tested by a Putiantongchuang WRX-5A apparatus. Optical rotations were measured on a Jasco-P-1020 polarimeter. IR spectra were obtained by using a Bruker Tensor 27 FT-IR spectrometer with $\mathrm{KBr}$ pellets. NMR spectra were acquired with instrument of a Bruker DRX-500. HRESIMS was measured on an API QSTAR Pulsar spectrometer. Silica gel (200-300 mesh and 80-100 mesh, Qingdao Marine Chemical Inc., China) and Sephadex LH-20 (Amersham Biosciences, Sweden) were used for column chromatography (CC). Fractions were monitored by TLC (Qingdao Marine Chemical Inc., China) and spots were visualized by heating silica gel plates immersed in vanillin- $\mathrm{H}_{2} \mathrm{SO}_{4}$ in EtOH, in combination with Agilent 1200 series HPLC system (Eclipse XDB-C18 column, $5 \mu \mathrm{m}, 4.6 \times 150$ $\mathrm{mm})$. Preparative HPLC was performed on an Agilent 1100 series with a Zorbax SB-C18 $(5 \mu \mathrm{m}, 9.4 \times 150 \mathrm{~mm})$ column. MPLC was performed on Buchi apparatus equipped with Buchi fraction collector C-660, Buchi pump module C-605 and manager C-615.

\section{Fungal material and cultivation conditions}

Fruiting bodies of $P$. ellisii were collected at Jingdong, Yunnan Province, China in 2003 and identified by Prof. Zhu-Liang Yang (Kunming Institute of Botany). The voucher specimen (no. CGBWSHF00118) was deposited at herbarium of Kunming Institute of Botany. Culture medium was composed of glucose $(5 \%)$, pork pepton $(0.15 \%)$, yeast $(0.5 \%), \mathrm{KH}_{2} \mathrm{PO}_{4}$ $(0.05 \%)$ and $\mathrm{MgSO}_{4}(0.05 \%)$. Initial $\mathrm{pH}$ was adjusted to 6.0 , the fermentation was first carried out on an Erlenmeyer flask for 6 days till the mycelium biomass reached to the maximum. Later 
it was transferred to a fermentation tank $(100 \mathrm{~L})$ at $24{ }^{\circ} \mathrm{C}$ and $250 \mathrm{rpm}$ for twenty days, ventilation was setted to $1.0 \mathrm{vvm}$ (vvm: air volume/culture volume/min).

\section{Extraction and isolation}

The culture broth (80 L) was extracted four times with EtOAc. The organic layer was evaporated to give a crude extract $(71 \mathrm{~g})$. Then it was subjected to silica gel CC (200-300 mesh) eluted with petroleum ether (PE)- $\mathrm{Me}_{2} \mathrm{CO}$ gradient system to afford fractions A-G. Fraction C, eluted with $\mathrm{PE}-\mathrm{Me}_{2} \mathrm{CO}(8 / 1)$, was separated by Sephadex LH-20 CC $\left(\mathrm{CHCl}_{3}-\mathrm{MeOH}, 1 / 1\right)$, then applied to preparative MPLC with a reversed-phased C18 column $\left(\mathrm{MeOH}-\mathrm{H}_{2} \mathrm{O}, 50-100 \%\right)$ and preparative HPLC (MeCN$\mathrm{H}_{2} \mathrm{O}, 0-20 \%, 10 \mathrm{~mL} \mathrm{~min}^{-1}$ ) to give 1 (4.8 $\mathrm{mg}$ ).

Polyellisin (1). Colorless crystal $\left(\mathrm{CHCl}_{3}\right) ; \operatorname{mp} 178{ }^{\circ} \mathrm{C}$; $[\alpha]_{\mathrm{D}}^{20}+105.3(c 0.05 \mathrm{MeOH}) ; \mathrm{UV}(\mathrm{MeOH}) \lambda_{\max }(\log \varepsilon) 202$ (3.61), 218 (3.70), 262 (3.16) nm; IR (KBr) $\nu_{\max } 3483,2972,2932,1708$, 1623, 1593, 1474, 1381, 1298, 1090, 1025, $960 \mathrm{~cm}^{-1} ;{ }^{1} \mathrm{H}$ and ${ }^{13} \mathrm{C}$ NMR data (see Table 1); HRESIMS (pos.) $m / z 387.1779$ (calcd for $\mathrm{C}_{20} \mathrm{H}_{28} \mathrm{O}_{6} \mathrm{Na}$, 387.1783).

Crystallographic data of polyellisin (1). $\mathrm{C}_{20} \mathrm{H}_{28} \mathrm{O}_{6}, M=$

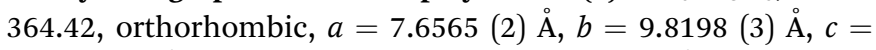

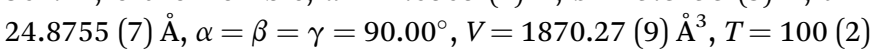
$\mathrm{K}$, space group $P 2_{1} 2_{1} 2_{1}, Z=4, \mu(\mathrm{CuK} \alpha)=0.779 \mathrm{~mm}^{-1}, 8819$ reflections measured, 3262 independent reflections $\left(R_{\text {int }}=\right.$ $0.0387)$. The final $R_{1}$ values were $0.0311(I>2 \sigma(I))$. The final $\mathrm{w} R$ $\left(F^{2}\right)$ values were $0.0790(I>2 \sigma(I))$. The final $R_{1}$ values were 0.0313 (all data). The final $\mathrm{w} R\left(F^{2}\right)$ values were 0.0792 (all data). The goodness of fit on $F^{2}$ was 1.059. Flack parameter $=0.07$ (14). The Hooft parameter is 0.08 (6) for 1286 Bijvoet pairs. Crystallographic data for the structure of polyellisin (1) have been deposited with the Cambridge Crystallographic Data Centre (deposition no. CCDC 936912).

\section{Cytotoxicity assay}

All the cells were cultured in RPMI-1640 or DMEM medium (Hyclone, USA), supplemented with 10\% fetal bovine serum (Hyclone, USA) in $5 \% \mathrm{CO}_{2}$ at $37^{\circ} \mathrm{C}$. The cytotoxicity assay was performed according to the MTT (3-(4,5-dimethylthiazol-2-yl)2,5-diphenyl tetrazolium bromide) method in 96-well microplates. Briefly, $100 \mu \mathrm{L}$ adherent cells were seeded into each well of 96-well cell culture plates and allowed to adhere for $12 \mathrm{~h}$ before drug addition, while suspended cells were seeded just before drug addition with initial density of $1 \times 10^{5}$ cells per $\mathrm{mL}$. Each tumor cell line was exposed to the test compound at concentrations of $0.0625,0.32,1.6,8$, and $40 \mu \mathrm{M}$ in triplicates for $48 \mathrm{~h}$, with cisplatin (sigma, USA) as a positive control. After compound treatment, cell viability was detected and cell growth curve was graphed.

\section{Anti-NO production assay}

Murine monocytic RAW264.7 macrophages were dispensed into 96-well plates $\left(2 \times 10^{5}\right.$ cells per well $)$ containing RPMI 1640 medium (Hyclone) with 10\% FBS under a humidified atmosphere with $5 \% \mathrm{CO}_{2}$ at $37{ }^{\circ} \mathrm{C}$. After $24 \mathrm{~h}$ of preincubation, cells were treated with serial dilutions of the test compounds, up to a maximum concentration of $25 \mu \mathrm{M}(n=2)$, in the presence of $1 \mu \mathrm{g} \mathrm{mL} \mathrm{mL}^{-1}$ LPS for $18 \mathrm{~h}$. The compounds were dissolved in DMSO and further diluted in medium to produce different concentrations. NO production in each well was assessed by adding $100 \mu \mathrm{L}$ of Griess reagent (reagent A and reagent B, Sigma) to $100 \mu \mathrm{L}$ of each supernatant from the LPStreated or LPS- and compound-treated cells in triplicate. After 5 min incubation, the absorbance of samples was measured at 570 nm with a 2104 Envision Multilabel Plate Reader (PerkinElmer Life Sciences, Inc., Boston, MA, USA). MG-132 (SigmaAldrich, purity 98\%) was used as a positive control $\left(\mathrm{IC}_{50}=\right.$ $2.8 \mu \mathrm{M}$ ). Compound 1 (purity $>90 \%$ ) were tested for inhibitory activity on NO production.

\section{Conflicts of interest}

There are no conflicts to declare.

\section{Acknowledgements}

This work was financially supported by the National Key Research and Development Program of China (2017YFC1704007), National Natural Science Foundation of China (81773590, 81872762, 31870513, 81561148013), Thailand Research Fund (grant no. DBG5980002), the Key Projects of Technological Innovation of Hubei Province (No. 2016ACA138), and the Fundamental Research Funds for the Central University, South-Central University for Nationalities (CZP18005, CZQ17010, CZQ17008, CZT18014, CZT18013). The authors thank the Analytical \& Measuring Center, School of Pharmaceutical Sciences, South-Central University for Nationalities for the spectra test.

\section{Notes and references}

1 H. D. Zheng and P. G. Liu, Fungal Divers., 2008, 32, 157-170. 2 J. M. Gao, A. L. Zhang, H. Y. Yao and J. Shen, Zhongguo Zhongyao Zazhi, 2003, 28, 943-945.

3 J. M. Gao, L. Hu, Z. J. Dong and J. K. Liu, Lipids, 2001, 36, 521-527.

4 J. K. Liu, Heterocycles, 2002, 57, 157-167.

5 S. Wang, L. Zhang, L. Y. Liu, Z. J. Dong, Z. H. Li and J. K. Liu, Nat. Prod. Bioprospect., 2012, 2, 240-244.

6 S. Wang, Z. H. Li, Z. J. Dong, J. K. Liu and T. Feng, Fitoterapia, 2013, 91, 194-198.

7 J. H. Ding, T. Feng, B. K. Cui, K. Wei, Z. H. Li and J. K. Liu, Tetrahedron Lett., 2013, 21, 2651-2654.

8 X. Y. Yang, T. Feng, Z. H. Li, Y. Sheng, X. Yin, Y. Leng and J. K. Liu, Org. Lett., 2012, 14, 5382-5384.

9 M. Y. Jiang, Y. Li, F. Wang and J. K. Liu, Phytochemistry, 2011, 72, 923-928.

10 Z. Y. Zhou, G. Q. Shi, R. Fontaine, K. Wei, T. Feng, F. Wang, G. Q. Wang, T. Qu, Z. H. Li, Z. J. Dong, H. J. Zhu, Z. L. Yang, G. Zeng and J. K. Liu, Angew. Chem., Int. Ed., 2012, 51, 23682370 .

11 Z. Z. Zhao, H. P. Chen, B. Wu, L. Zhang, Z. H. Li, T. Feng and J. K. Liu, J. Org. Chem., 2017, 82, 7974-7979. 
12 S. B. Zhang, Y. Huang, S. J. He, H. P. Chen, Z. H. Li, B. Wu, J. P. Zuo, T. Feng and J. K. Liu, RSC Adv., 2018, 8, 2391423918.

13 T. Mosmann, J. Immunol. Methods, 1983, 65, 55-63.
14 S. B. Zhang, Z. H. Li, M. Stadler, H. P. Chen, Y. Huang, X. Q. Gan, T. Feng and J. K. Liu, Phytochemistry, 2018, 152, 105-112. 